\title{
DIMENSIONES BIOÉTICAS DE LA INVESTIGACIÓN SOBRE EL GENOMA HUMANO
}

\author{
Ricardo B. Maccioni, Juan P. Muñoz y Cristóbal Maccioni*
}

\begin{abstract}
Resumen: El desciframiento del genoma humano es un paradigma de la ciencia. Además de impactar en el conocimiento puede cambiar el curso de la medicina, con un enfoque personalizado y un énfasis en lo preventivo. Como los hallazgos que abren nuevas avenidas de pensamiento, ha despertado la atención sobre los riesgos éticos. Se plantea si es ético que le revelen a un individuo que podría llegar a padecer una enfermedad incurable, lo que impactaría negativamente en su calidad de vida. Sobre quién tendrá acceso a la información genética. Desde los inicios de la carrera del genoma humano se planteó la necesidad de asegurar la privacidad de la información genética. Se hace necesario situar la discusión en un contexto amplio, pues se crean mitos que es importante aplacar. Es esencial sembrar la confianza promoviendo que la comunidad científica, junto con diferentes sectores de la sociedad, realicen un debate abierto sobre los aspectos positivos y negativos de cada nueva tecnología que derive del genoma humano.
\end{abstract}

Palabras clave: Ética, investigación, genoma

\section{BIOMEDICAL DIMENSIONS ON HUMAN GENOME RESEARCH}

\begin{abstract}
The elucidation of the human genome constitutes a major paradigm. Besides its impact on our biological knowledge, the elucidation of the human genome will certainly exert a driving force on both medical research and practice in the future. As a paradigmatic discovery impacting medical research, the human genome has also increased public awareness concerning the risks and ethical problems associated with this advancement. Questions such as whether it is ethical to reveal to a patient that he may be suffering an incurable disease, that this information may negatively impact his quality of life are among the many concerns. From the beginning of the race to elucidate the human genome, it was agreed upon that it is necessary to assure the privacy of an individual genetic information. Therefore, it is critical to focus the discussion in a wide scope and integrative perspective, since myths appear that may produce distortions in the analysis. It is also important to trust that the scientific community, together with other public sectors of the society, will promote a debate associated with the positive and negative aspects of any new technology arising from the discoveries around human genome. It is not the scientific advances that cause bioethical problems, it is the decisions that society takes in terms of how this technology will be used.
\end{abstract}

Key Words: Ethics, Research, Genome

\section{DIMENSÕES BIOÉTICAS DA PESQUISA SOBRE O GENOMA HUMANO}

Resumo: O mapeamento do genoma humano é uma paradigma para a ciência. Além de impactar no conhecimento, pode mudar o curso da medicina, com um enfoque personalizado e ênfase no preventivo. Como os hallazgos que abrem novas avenidas de pensamento, desertou a atenção sobre os riscos éticos. Pergunta-se de é ético que se revele a um indivíduo que poderia chegar a padecer de uma enfermidade incurável, o que impactaria negativamente sua qualidade de vida. Quem terá acesso à informação genética? Desde o início do processo de mapeamento do genoma humano se colocou a necessidade de assegurar a privacidade da informação genética. Torna-se necessário situar a discussão num contexto mais amplo, pois se criam mitos que é importante enfrentar. É essencial semear a confiança promovendo que a comunidade científica, junto com os diferentes setores da sociedade, realizem um debate aberto sobre os aspectos positivos e negativos de cada nova tecnologia que derive do genoma humano.

Palavras chave: Ética, pesquisa, genoma

Millennium Institute for Advanced Studies in Cell Biology and Biotechnology, Facultad de Ciencias, Universidad de Chile. Correspondencia: rmaccion@uchile.cl 


\section{Introducción}

Hacia fines de 1999 la prestigiosa revista Nature publicaba un artículo que informaba la secuenciación del cromosoma 22 humano(1). Sólo un año después la revista Science publica el resultado de la investigación sobre la secuenciación del genoma de la mosca de la fruta Drosophila melanogaster, fruto de la colaboración entre biólogos moleculares, genetistas y bioinformáticos de diferentes países, coordinados por el grupo de Craig Venter(2). Sin embargo, el impacto más significativo ocurrió sólo unos meses después, a comienzos del año 2001, cuando, en la misma revista, se publicó el desciframiento del genoma humano prácticamente completo $(3,4)$. En esta avasalladora investigación, se ha logrado dilucidar en los últimos años un número creciente de genomas (figura 1). Uno de los elementos clave para este avance hacia la dilucidación del genoma humano mucho antes de lo que se proyectaba para llegar a la completa secuenciación fue, sin duda, el enfoque moderno y ultrarrápido derivado de los estudios de Venter sobre las secuencias EST descritas en 1991(5) y la aplicación del méto- do de "shotgun"(6). Si se compara este revolucionario método con otras técnicas se aprecia la diferencia en el tiempo en que se logra dilucidar un genoma. Este método consiste en fragmentar el DNA del organismo en estudio en segmentos identificables, que son aislados y secuenciados, para luego colocarlos en forma continua y solapada hasta obtener la secuencia del genoma.

\section{El dilema de la ponderación de factores genéticos y ambientales}

El genoma es el total de genes y cromosomas de un organismo. Los genes expresan su información en proteínas que cumplirán una función en el organismo. Si bien existe un solo genoma para un determinado organismo, pueden existir varios proteomas, lo que ha llevado a apoyar la idea de que un individuo es el resultado de sus genes, pero también de su historia y de sus interacciones con el medio ambiente. Los genes contienen información para las diferentes funciones en un organismo, pero los biólogos moleculares saben hoy que el procesamiento y modificaciones post-

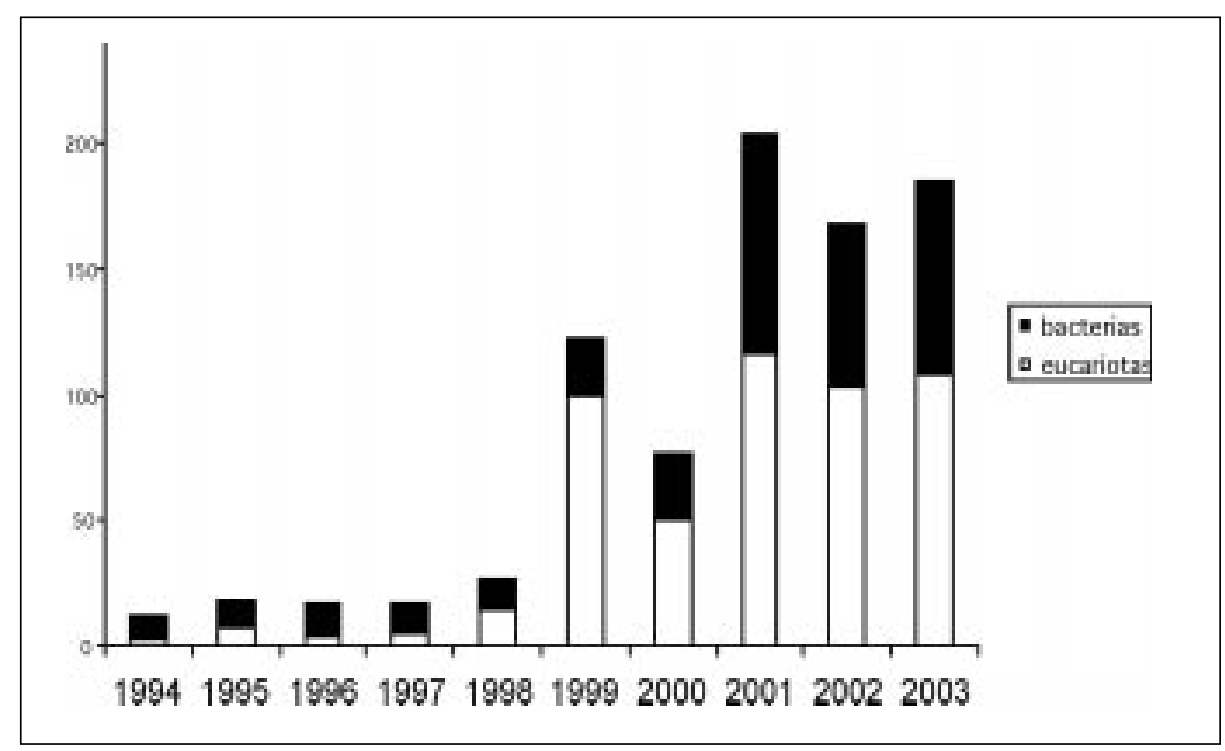

Figura 1. Número de genomas de diferentes organismos que han sido ya secuenciados, o que su secuenciación está en progreso desde el año 1994 a Octubre del 2003. 


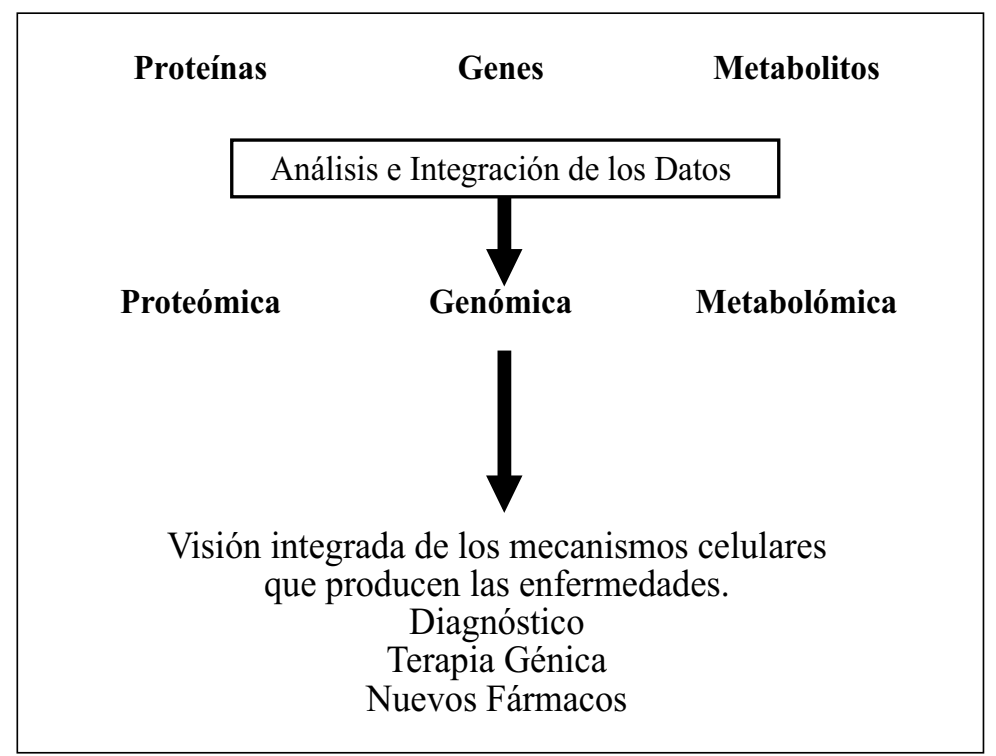

Figura 2. Relación entre genes, proteínas, metabolitos y los grandes dominios de investigación que se abren hacia el futuro, los que impactarán en la medicina moderna, y en relación con los cuales es importante investigar sus connotaciones bioéticas.

traduccionales en las proteínas cumplen un papel clave en la regulación de la maquinaria celular. El conocimiento biológico a través de la genómica está abriendo caminos para definir los genes involucrados en determinadas enfermedades, los mecanismos que causan estas dolencias y los blancos a los cuales dirigir los modernos enfoques terapéuticos. Así, en gran medida, la medicina del futuro dependerá de la dilucidación de la genómica funcional y la dinámica de cómo se expresan y se reprimen ciertos genes durante el funcionamiento de una célula, pero también de la proteómica y la metabolómica(7) (figura 2).

En el estudio de Venter, el desciframiento del genoma humano general corresponde a la secuencia estadística obtenida de 3 mujeres y 2 hombres considerando que existen mínimas diferencias entre cada individuo, pues tienen en común el 99,99\% de sus genomas. Ello tiene implicaciones muy importantes desde el punto de la bioética. Efectivamente, el hombre y otros primates comparten el $98 \%$ de sus genomas. Por otra parte, el hombre y el ratón tienen un número equivalente de genes, pero comparten alrededor del $96 \%$ de sus genomas. Ello da una idea de las similitudes de los genomas entre los mamíferos, y del hecho de que el número de genes no guarda relación con la posición de las especies dentro del esquema evolutivo, sino más bien está definido por el contenido de información de estos genes y sus mecanismos de procesamiento.

\section{Cuestiones éticas del genoma humano para los individuos y para la sociedad}

El desciframiento del genoma humano ha significado una apertura conceptual importante que, además de impactar en el conocimiento biológico, puede cambiar el curso de la medicina en el futuro, con un enfoque personalizado y un mayor énfasis en lo preventivo. Como otros hallazgos que han abierto nuevas avenidas de pensamiento científico, ha despertado la atención sobre la otra cara del genoma: los riesgos éticos de este conocimiento. Los indi- 
viduos, instituciones y la sociedad en general se enfrentarán a situaciones en las que se fomentarán ciertos intereses y se perjudicarán otros. ¿Qué intereses debe priorizar la sociedad(8)? La ética y las políticas públicas: el problema de "qué debe hacerse". Se plantean interrogantes, tales como si es ético revelar a un individuo que podría llegar a padecer una enfermedad incurable de aquí a unos años, lo que impactaría negativamente en su calidad de vida. Conocer que uno o varios genes son responsables de cierta enfermedad no implica saber cómo se cura y, en efecto, se han aislado ya varios genes implicados en dolencias que aún no tienen remedio.

Se plantean cuestiones para los individuos y para la sociedad, como las relativas al acceso. Los genetistas usarán datos del genoma general y, por otra parte, datos a partir del genoma de un individuo para definir su genoma personal. El genoma personal es un registro médico que plantea múltiples cuestiones, entre ellas las relativas a la confidencialidad de los datos. El tema de quién tendrá acceso a la información genética es crítico, pues ello puede torcer el curso de muchas decisiones en la vida de los seres humanos. Desde los inicios de la carrera del genoma se planteó la necesidad de asegurar la privacidad absoluta de la información genética de cada individuo. Se revelan escenarios como el que las empresas contraten a la gente en función de su calidad genética, que las aseguradoras médicas privadas no suscriban pólizas con pacientes de riesgo o que se realicen prácticas eugenésicas.

\section{Las expectativas del proceso científico y los marcos de la bioética}

Más allá de sus inevitables derivaciones éticas, se hace necesario situar la discusión en un contexto más amplio. Se crean muchos mitos que es importante aplacar. Lo esencial es sembrar la confianza en la sociedad, gene- rando un debate abierto en la comunidad de hombres de ciencia y otros sectores sobre los aspectos positivos y negativos de las nuevas tecnologías que deriven del conocimiento del genoma humano. Es importante no crear falsas expectativas cuando irrumpe una nueva forma de terapia para controlar enfermedades terminales, pues la información del genoma nos dice cuál es el cuadro de probabilidades de una nueva vía en el tratamiento médico. Por ejemplo, si bien existieron esperanzas sobre la terapia génica de células somáticas por la vía de vectores biológicos, sus resultados han sido poco alentadores y muy limitados, puesto que la mayor parte de las dolencias involucran no a un solo gen, sino a varios(9) y la inmensa mayoría de las enfermedades es de tipo esporádico y no se debe a un gen específico, aunque, obviamente, puede haber genes que incidan en la probabilidad de adquirirlas. La terapia de línea germinal, por otra parte que implica la intervención en óvulos y espermatozoides- implica cambios de la dotación genética de un individuo, por lo que es éticamente cuestionable y no está aprobado su uso en estudios clínicos.

La genómica tiene una gran responsabilidad y un papel importante en nuestra sociedad del conocimiento.

Toda la organización social del hombre, las formas de adecuarse al entorno y a la naturaleza, surgen de nuestro cerebro y éste es el fundamento de todo lo que creamos, racionalizamos y sentimos, el fundamento de la creatividad. La genómica funcional, que nos acerque a comprender cómo operan los genes en la actividad neuronal y sus conexiones con otras células cerebrales, cobra especial vigor en esta era.

La genómica, sumada a los enfoques multidisciplinarios de la proteómica, de la biología celular y las neurociencias, abre renova- 
das expectativas para la investigación médica en beneficio de una mejor calidad de vida. El genoma, entre otros múltiples impactos, nos puede ayudar a combatir plagas y enfermedades contagiosas que producen efectos devastadores en la salud humana.

Por otra parte, un fuerte debate nacional e internacional se ha generado por los nuevos hitos en el controvertido tema de la clonación humana, en el cual existe un vacío de información a nivel global(10). Existen varios tipos de clonación. El primero es el de la clonación embrionaria, que puede ocurrir en forma natural, cuando, básicamente, se dividen las células del embrión, se separan y, a partir de éstas, se generan dos clones. La segunda forma de clonación, utiliza DNA no embrionario, sino adulto. Ésta es la técnica que se ocupó en el caso de la oveja Dolly, y estudios realizados también con otros primates como Mono Rhesus. Es indudable que ello genera un fuerte y serio debate por los aspectos éticos involucrados que, definitivamente, existen y son de relevancia, pues es inaceptable plantear este tipo de escenarios en seres humanos. Pero hay posibilidades de otro tipo de clonación del cual, en general, se habla poco, pero cuyas proyecciones merecen un análisis filosófico y bioético y que, según algunos, si se realiza dentro de un estricto marco regulador, podría redundar en avances relevantes para la calidad de vida del ser humano. Se trata de la clonación con fines terapéuticos(11). Algunos países han dado el visto bueno a este tipo de estudios, en tanto otros han legislado para que no se investigue en esa dirección. En tanto, el foro de las Naciones Unidas tuvo una posición dividida al respecto. Esta técnica utiliza el mismo procedimiento de clonación del DNA, pero aplicándolo a fines terapéuticos, y se plantea que podría lle- gar a ofrecer una vía para generar bancos de células madre para trasplantes evitando el rechazo inmunológico. Considerando los problemas bioéticos que este enfoque presenta, resulta prudente investigar más a fondo en el uso de células madre del adulto para fines terapéuticos, pues ésta no involucra la participación de ovocitos y, por lo tanto, de células madre embrionarias(11), aunque ello requiera un tiempo mucho mayor de investigación para futuros usos médicos. Los progresos significativos en la investigación genómica, de la biología celular y las neurociencias están entregando valiosa información para el progreso de la medicina. Así, el conocimiento sobre el genoma humano ha significado un gran paradigma en la ciencia moderna y un hito importante en la historia de la humanidad que abre un nuevo horizonte no sólo a la medicina moderna, sino a la filosofía, el derecho y las humanidades. Para finalizar, quisiera destacar la importancia de confiar en la comunidad científica como un todo. El célebre James D. Watson, laureado con el Premio Nobel por su hallazgos sobre la estructura del DNA, 1o enfatizaba en una conferencia reciente en Londres, donde argumentaba la necesidad de disipar los temores y no entrabar la creatividad de los científicos, pues ésta asegurará un mundo mejor. Cuando irrumpió la era de las proteínas recombinantes(12) se pensó en escenarios de terror en los que bacterias recombinantes podrían invadir las ciudades y el planeta; nada de eso ha ocurrido y, así, muchos otros ejemplos. En suma, el trabajo multidisciplinario de científicos, bioeticistas e investigadores en las ciencias humanas debería ser la forma para continuar construyendo futuro para el hombre en el planeta.

Esta investigación ha sido financiada por el proyecto Fondecyt 1020155 y el proyecto Iniciativa Milenio P99031F, Mideplan, Chile. 


\section{Referencias}

1. Dunham I, Shimizu N, Roe BA, et al. The DNA sequence of human chromosome 22. Nature 1999; 402: 489-95.

2. Adams MD, Celniker SE, Holt RA, et al. The genome sequence of Drosophila melanogaster. Science 2000; 287: 2185-95.

3. Venter JC, Adams MD, Myers EW, et al. The sequence of the human genome. Science 2001; 291: 1304-51.

4. Lander ES, Linton LM, Birren B, et al. International Human Genome Sequencing Consortium. Initial sequencing and analysis of the human genome. Nature 2001; 409: 860-921.

5. Adams MD, Soares MB, Kerlavage AR, et al. Rapid cDNA sequencing (expressed sequence tags) from a directionally cloned human infant brain cDNA library. Nature Genetics 1993; 4: 373-80.

6. Venter JC, Adams MD, Sutton GG, et al. Shotgun sequencing of the human genome. Science 1998; 280: $1540-2$.

7. Ge H, Walhout AJ, Vidal M. Integrating 'omic' information: a bridge between genomics and systems biology. Trends in Genetics 2003; 19: 551-60.

8. San Martín J, Grisolía S. Genoma Humano. Ciencia, ética y política pública. Generalitat Valenciana: Ediciones Alfons et Magnanim; 1994.

9. Griesenbach U, Ferrari S, Geddes DM, Alton EW. Gene therapy progress and prospects: cystic fibrosis. Gene Therapy 2002; 9: 1344-50.

10. Leader DP. Reproductive cloning: an attack on human dignity. Nature 2003; 424:14.

11. Jiang Y, Jahagirdar BN, Reinhardt RL, et al. Pluripotency of mesenchymal stem cells derived from adult marrow. Nature 2002; 418: 41-49.

12. Russell CS, Clarke LA. Recombinant proteins for genetic disease. Clinical Genetics 1999; 55: 389-94. 